Jurnal Ilmiah Ibnu Sina, 6(1), Maret 2021, 39-48

p-ISSN: 2502-647X; e-ISSN: 2503-1902

\title{
PENGARUH VARIASI KONSENTRASI AMPROTAB SEBAGAI DESINTEGRANT TERHADAP SIFAT FISIK TABLET EKSTRAK BUAH PARE (MOMORDICA CHARANTIA L.)
}

\author{
Sri Rahayu*, Nor Anisah \\ Universitas Muhammadiyah Banjarmasin \\ *Email : rahayu.dds15@gmail.com \\ Artikel diterima: 06 September 2020; Disetujui: 27 Februari 2021 \\ DOI: https://doi.org/10.36387/jiis.v6i1.572
}

\begin{abstract}
ABSTRAK
Buah pare (Momordica charantia L.) merupakan salah satu jenis tanaman obat yang banyak digunakan oleh masyarakat. Charantin merupakan salah satu senyawa berkhasiat yang terkandung dalam pare. Senyawa charantin dapat digunakan untuk menurunkan kadar glukosa dalam darah sehingga banyak digunakan sebagai obat diabetes. Penelitian ini bertujuan untuk mengetahui pengaruh variasi konsentrasi amprotab sebagai bahan penghancur terhadap sifat fisik tablet ekstrak pare (Momordica charantia L.). Ekstrak kental dibuat dengan metode maserasi menggunakan etanol $96 \%$. Tablet dibuat dengan metode granulasi basah pada dua konsentrasi bahan penghancur yang berbeda yaitu 9,6\% dan $18 \%$. Granul kering diuji dengan flowabilitas, sudut diam dan indeks kompresibilitas. Evaluasi tablet meliputi uji keseragaman bobot, uji kerapuhan, uji kekerasan dan uji hancur. Hasil penelitian menunjukkan bahwa formula dengan amprotab sebagai bahan penghancur pada konsentrasi 9,6\% mampu menghasilkan tablet yang memenuhi persyaratan. Variasi konsentrasi bahan penghancur berpengaruh terhadap keseragaman bobot, kerapuhan, kekerasan dan waktu hancur tablet.
\end{abstract}

Kata kunci: Ekstrak Buah Pare (Momordica Charantia L.), Bahan Penghancur Amprotab, Granulasi Basah

\begin{abstract}
Bitter melon (Momordica charantia L.) is a type of medicinal plant that is widely used by the public. Charantin is one of the nutritious compounds contained in bitter melon. Charantin compounds can be used to reduce glucose levels in the blood so that it is widely used as a diabetes medicine. The research aims to determine the effect of variations in the concentration of amprotab as a desintegrant on the physical properties of Pare (Momordica charantia L.) extract tablets has been conducted. Viscous extract was made by maceration method by using ethanol $96 \%$. Tablets made by wet granulation method in two different desintegrant concentration of $9,6 \%$ and $18 \%$. Dried granule tested with flowability, angle of repose and indeks of compressibility. Tablet evaluation includes uniformity of weight test, friability test, hardness test and disintegration test. The results showed that formula with amprotab as desintegration at 9,6\% concentration was able to produce tablets that met the requirements. Variation in concentration of
\end{abstract}


Jurnal Ilmiah Ibnu Sina, 6(1), Maret 2021, 39-48

p-ISSN: 2502-647X; e-ISSN: 2503-1902

desintegrant material take effect on the uniformity of weight, hardness friability and disintegration time.

Keywords: Bitter melon (Momordica Charantia L.) extract, desintegrant, Amprotab, wet granulation

\section{PENDAHULUAN}

Kencing manis (Diabetes

Mellitus) merupakan penyakit global dengan jumlah penderita sekitar $4 \%$ populasi dunia dengan peningkatan yang signifikan. Penyakit ini ditandai dengan meningkatnya kadar glukosa darah. Pada penderita diabetes mellitus kadar glukosa di dalam darah tinggi dan sukar untuk kembali normal karena tubuh tidak dapat melepaskan atau menggunakan insulin secara cukup (Grover et al, 2002).

Lebih dari 400 tumbuhtumbuhan telah diketahui dapat memberikan efek penurunan kadar glukosa darah. Salah satu tumbuhan obat yang banyak digunkan secara tradisional untuk pengobatan diabetes mellitus adalah buah pare (Momordica charantia L.). Salah satu senyawa berkhasiat yang terkandung dalam buah pare adalah charantin. Senyawa charantin berkhasiat untuk menurunkan kadar glukosa dalam darah sehingga banyak digunakan sebagai obat antidiabetes atau kencing manis (Jaya, 2007).

Tanaman pare banyak dikenal dalam masyarakat untuk penyembuhan berbagai penyakit. Namun banyak orang yang tidak menyukai rasa pahit dari tanaman pare. Umumnya pemanfaatan buah pare masih dalam bentuk ekstrak segar. Sehingga untuk meningkatkan kepraktisan dan stabilitasnya perlu dikembangkan bentuk sediaan lain yang lebih baik dan praktis. Salah satu alternatif bentuk sediaan yang dapat dikembangkan adalah tablet ekstrak buah pare. Sedangkan saat ini sudah banyak penelitian baik praklinis maupun klinis yang membuktikan potensi buah pare. Pemikiran tersebut yang melatarbelakangi pemanfaatan ekstrak buah pare sebagai salah satu bahan alami yang digunakan untuk pengobatan diabetes mellitus dengan bentuk sediaan yang lebih praktis digunakan. Salah satu sediaan farmasi yang praktis adalah sediaan tablet, dimana bentuk sediaan ini mempunyai 
Jurnal Ilmiah Ibnu Sina, 6(1), Maret 2021, 39-48

p-ISSN: 2502-647X; e-ISSN: 2503-1902

beberapa keuntungan, diantaranya diabsorbsi adalah terjadinya proses adalah mudah untuk dikonsumsi, disintegrasi. Bahan penghancur praktis, takarannya tepat, dikemas berfungsi untuk menghancurkan tablet secara baik, praktis transportasi dan jika tablet kontak dengan cairan, penyimpanannya (stabilitasnya terjaga sehingga selanjutnya luas permukaan dalam sediaannya) serta mudah ditelan, sehingga diharapkan tablet menjadi lebih luas, dan kecepatan pelepasan obat menjadi masyarakat dapat tertarik untuk mengkonsumsi sediaan tablet ekstrak buah pare.

Kandungan senyawa dari buah pare yaitu: alkaloid momordisin, karoten glikosida, saponin, sterol/terpen. Kandungan zat aktif ekstrak buah pare tahan panas dan stabil terhadap air, berdasarkan sifatsifat tersebut maka metode pembuatan tablet ini sesuai dengan metode granulasi basah (Grover et al, 2002).

Pada suatu sediaan farmasi, selain zat aktif juga dibutuhkan eksipen/ bahan tambahan. Salah satu bahan tambahan yang penting dalam pembuatan tablet adalah bahan penghancur. karena waktu hancur tablet sangat menentukan kelarutan zat aktif obat dalam tubuh dan tercapainya bioavailabilitas yang diharapkan. Obat harus berada dalam bentuk larutan agar segera bisa diabsorbsi. Tahapan pertama yang terjadi sebelum obat lebih cepat (Siregar \& Wikarsa, 2010).

Oleh karena itu penambahan penghancur sangat penting pada pembuatan tablet ekstrak buah pare. Bahan penghancur pada pembuatan tablet ekstrak buah pare adalah Amprotab. Amprotab merupakan nama dagang dari Amylum Manihot. Amylum digunakan sebagai bahan penghancur (disintegrant) pada konsentrasi 3-15\% (Rowe et al, 2009). Amprotab mempunyai kekuatan pada aksi kapiler. yang mana akan membentuk suatu cairan yang masuk ke dalam tablet, aksi ini akan melawan aksi bahan pengikat dan aksi ini akan membantu pengembangan dari beberapa komponen yang akan membantu hancurnya tablet. Pati mempunyai sifat hidrofilik yang mampu menyerap air dan membentuk pori-pori dalam tablet. Hal tersebut akan meningkatkan penetrasi air ke dalam tablet sehingga akan 
Jurnal Ilmiah Ibnu Sina, 6(1), Maret 2021, 39-48

p-ISSN: 2502-647X; e-ISSN: 2503-1902

mempercepat waktu hancur tablet (Rowe et al, 2009).

Berdasar uraian di atas, maka perlu dilakukan penelitian tentang pengaruh variasi konsentrasi bahan penghancur amprotab terhadap sifat fisik tablet ekstrak buah pare (Momordica charantia L)

\section{METODE PENELITIAN}

Peralatan yang digunakan dalam penelitian ini adalah botol, gelas ukur, corong, timbangan analitik, beker glass, kompor listrik, waterbath, batang pengaduk, hair dryer, mortir, stamper, ayakan 14 mesh, ayakan 12 mesh, oven, cawan petri, hardness tester, friability tester dan alat pencetak tablet.

Bahan yang digunakan dalam penelitian ini adalah ekstrak buah pare, etanol 96\%, laktosa, gelatin, amprotab (Amilum Manihot), magnesium stearate dan talkum.

\section{Tahapan pengambilan data}

Buah pare dikupas dan dibersihkan dengan air, dirajang dan dijemur menjadi simplisia.

\section{Pembuatan Simplisia}

Buah pare dicuci menggunakan air mengalir, setelah bersih dilakukan perajangan atau memotong buah pare menjadi tipis, dan lakukan pengeringan dengan sinar matahari, ditutup menggunakan kain berwarna hitam, setelah kering, dilakukan sortasi kering atau pemisahan dari simplisia pare dengan bahan pencemar. Ekstraksi dilakukan dengan menimbang \pm 500 gram simplisia, masukkan kedalam botol berwarna hitam, tambahkan etanol 96\% tutup botol dan dimaserasi selama 3 hari. Hasil penyaringan kemudian diuapkan hingga diperoleh ekstrak kental.

Tabel 1. Formula

\begin{tabular}{|c|c|c|}
\hline \multirow[t]{2}{*}{ Komposisi } & \multicolumn{2}{|c|}{$\begin{array}{c}\text { Formula } 1 \\
\text { tablet }\end{array}$} \\
\hline & F1 & F2 \\
\hline Fase Dalam: & 100 & $100 \mathrm{mg}$ \\
\hline Ekstrak buah pare & $\mathrm{mg}$ & \\
\hline Adsorben & & $100 \mathrm{mg}$ \\
\hline Gelatin & 100 & $1,2 \%$ \\
\hline Amprotab & $\mathrm{mg}$ & $12 \%$ \\
\hline \multirow[t]{2}{*}{ Laktosa } & $\begin{array}{l}1,2 \% \\
6 \%\end{array}$ & Qs \\
\hline & qs & \\
\hline Fase $\quad$ Luar: & $3,6 \%$ & $6 \%$ \\
\hline Amprotab & $2 \%$ & $2 \%$ \\
\hline Mg stearate & \multicolumn{2}{|c|}{ Talkum } \\
\hline \multicolumn{3}{|c|}{ Campurkan seluruh fase dalam } \\
\hline \multirow{2}{*}{\multicolumn{3}{|c|}{$\begin{array}{l}\text { (Ekstrak kental buah pare yang telah } \\
\text { dikeringkan dengan Adsorben (Avicel }\end{array}$}} \\
\hline & & \\
\hline \multicolumn{3}{|c|}{ PH 102), Amprotab, Laktosa gerus } \\
\hline hingga homoge & & emudian \\
\hline tambahkan deng & & \\
\hline
\end{tabular}


Jurnal Ilmiah Ibnu Sina, 6(1), Maret 2021, 39-48

p-ISSN: 2502-647X; e-ISSN: 2503-1902

(Amprotab, Mg Stearat dan Talkum)

hingga homogen, lalu tambahkan

dengan Gelatin dan gerus hingga

diperoleh massa yang dapat dikepal,

lalu adonan diayak dengan ayakan 12

mesh kemudian dikeringkan didalam

oven $40-50^{\circ} \mathrm{C}$ selama 3 jam.

\section{Pencetakan Tablet}

Granul kemudian dicetak dengan bobot $500 \mathrm{mg}$ pada tekanan tertentu dengan mesin pencetak tablet kemudian dilakukan evaluasi tablet.

\section{Evaluasi Granul}

\section{Sudut Diam (Sudut Istirahat/Sudut}

\section{Reposa)}

Untuk pengukuran sudut diam, sejumlah sampel ditimbang ( \pm 100 gram) dimasukkan kedalam corong alir, lalu permukaannya diratakan. Sampel dibiarkan mengalir dan susut diam ditentukan dengan mengukur sudut kecuraman bukti yang dihitung seperti berikut:

Keterangan:

$$
\operatorname{Tan} \alpha=\frac{h}{r}
$$

$\alpha=$ Sudut Diam $\left(^{\circ}\right)$

$\mathrm{h}=$ Tinggi Bukit $(\mathrm{cm})$

$\mathrm{r}=$ Jari-Jari Alas Bukit $(\mathrm{cm})$

\section{Uji Waktu Alir}

Waktu alir merupakan waktu yang diperlukan oleh sejumlah granul mengalir. Alat yang digunakan adalah flowmeter, dengan cara memasukkan 100 g granul ke dalam alat, buka penutup corong yang ada dibawah dan hitung waktu yang diperlukan oleh seluruh granul untuk mengalir melalui corong tersebut. Laju alir dinyatakan dalam gram/detik, waktu alirnya tidak boleh lebih dari 10 detik. Apabila 100 gram serbuk mempunyai waktu alir lebih dari 10 detik, akan mengalami kesulitan pada saat penabletan (Siregar \& Wikarsa, 2010).

\section{Persen Pengetapan}

Timbang $100 \mathrm{ml}$ granul sebagai (Vo), masukkan ke gelas ukur dan dicatat volumenya, kemudian catat perubahan volume pada tap ke 5, 10, 15 dan seterusnya sampai volume konstan dan dicatat sebagai (Vt), kemudian bobot granul ditimbang. Persen pengetapan yang baik yaitu $<20 \%$ (Siregar dan Wikarsa, 2010).

Perhitungan: $\frac{V o-V t}{V 0} \times 100 \%$

Keterangan:

$\mathrm{Vo}_{\mathrm{O}}=$ Volume granul sebelum dimampatkan $(\mathrm{ml})$

$\mathrm{Vt}=$ Volume granul setelah dimampatkan (ml)

\section{Evaluasi Tablet}

\section{Uji Keseragaman Bobot}

Ambil sebanyak 20 tablet dari masing-masing formula, timbang 
Jurnal Ilmiah Ibnu Sina, 6(1), Maret 2021, 39-48

p-ISSN: 2502-647X; e-ISSN: 2503-1902

seluruh tablet, hitung rata-rata bobot tablet kemudian timbang tablet satupersatu. Untuk persyaratan uji keseragaman bobot yaitu tidak boleh lebih dari 2 tablet yang menyimpang dari kolom A dan tidak boleh ada satupun tablet yang menyimpang dari kolom B (Anonim, 1979).

Tabel 2. Tabel Syarat Keseragaman Bobot

\begin{tabular}{lcc}
\hline \multirow{2}{*}{ Berat Rata-Rata } & \multicolumn{2}{c}{ Selisih (\%) } \\
\cline { 2 - 3 } & A & B \\
\hline$\leq 25 \mathrm{mg}$ & 15 & 30 \\
$26-150 \mathrm{mg}$ & 10 & 20 \\
$151-300 \mathrm{mg}$ & 7,5 & 15 \\
$>300 \mathrm{mg}$ & 5 & 10 \\
\hline
\end{tabular}

\section{Uji Kekerasan Tablet}

Siapkan sebanyak 10 tablet dari masing-masing formula, siapkan hardness tester, ambil satu buah tablet letakkan tegak lurus pada hardness tester, kemudian ditekan, lihat pada tekanan berapa tablet tersebut pecah. Syarat kekerasan tablet umumnya 4-8 kg (Anonim, 1995).

\section{Uji Kerapuhan Tablet}

Siapkan sebanyak 20 tablet dari masing-masing formula, bersihkan tablet dari debu menggunakan kuas, timbang 20 tablet tersebut, catat bobot keseluruhan, masukkan 20 tablet kedalam friability tester dengan kecepatan 25 rpm selama 4 menit (100 kali putaran), kemudian keluarkan tablet, bersihkan tablet dengan kuas, timbang bobot tablet sesudah dimasukkan kedalam alat, hitung selisih bobot tablet sebelum dan sesudah perlakuan. Persyaratan kerapuhan yaitu 0,5-1\% (Anonim, 1995).

Perhitungan:

$$
\mathrm{F}=\frac{a-b}{a} \times 100 \%
$$

Keterangan:

$\mathrm{a}=$ Bobot total tablet sebelum diuji

$\mathrm{b}=$ Bobot total tablet setelah diuji

\section{Uji Waktu Hancur}

Siapkan alat untuk menguji yaitu disintegration tester lalu siapkan sebanyak 6 tablet, kemudian masukkan 6 tablet tersebut kedalam keranjang alat, turun naikkan keranjang alat secara teratur 30 kali tiap menit. Tablet dinyatakan hancur jika tidak ada bagian tablet yang tertinggal diatas kaca, kecuali dinyatakan lain. Waktu untuk menghancurkan tablet biasa yaitu kurang dari 15 menit (Anonim, 1979)

\section{HASIL DAN PEMBAHASAN}

Tablet ini dibuat dengan metode granulasi basah agar diperoleh laju air

Sri Rahayu \& Nor Anisah | 44 
Jurnal Ilmiah Ibnu Sina, 6(1), Maret 2021, 39-48

p-ISSN: 2502-647X; e-ISSN: 2503-1902

dan komprebilitas yang baik sehingga akan dihasilkan tablet yang memenuhi persyaratan farmakope. Penelitian ini membuat 2 formulasi dengan menggunakan variasi konsentrasi bahan penghancur Amprotab, yaitu 9,6 \% dan $18 \%$. Tablet yang dibuat memiliki bobot $500 \mathrm{mg}$. Perbedaan bobot atau konsentrasi Amprotab pada kedua formula tersebut bertujuan untuk mengetahui pengaruh konsentrasi bobot Amprotab terhadap sifat fisik tablet.

Sebelum dilakukan pencetakan tablet, terlebih dahulu dilakukan evaluasi granul yaitu uji waktu alir dan sudut diam serta uji pengetapan. Tujuan dilakukannya evaluasi granul yaitu agar saat pencetakan nanti dapat menghasilkan tablet yang baik. Hasil uji sifat fisik granul dapat dilihat pada tabel berikut :

Tabel 3. Uji Sifat Fisik Granul

\begin{tabular}{cccc}
\hline \multirow{2}{*}{ No } & Uji Sifat & \multicolumn{2}{c}{ Formula } \\
\cline { 3 - 4 } & Fisik Granul & $\mathbf{1}$ & $\mathbf{2}$ \\
\hline \multirow{2}{*}{1} & Waktu alir & 8,90 & 9,51 \\
& granul & detik & detik \\
2 & Sudut diam & $29,68^{\circ}$ & $26,56^{\circ}$ \\
3 & \% pengetapan & 90 & 89 \\
\hline
\end{tabular}

Selanjutnya uji waktu alir dilakukan bertujuan untuk mengetahui kemampuan mengalirnya massa granul yang dapat mempengaruhi keseragaman bobot tablet, karena sifat alir granul yang baik merupakan hal yang penting untuk pengisian yang seragam kedalam lubang cetak mesin tablet. Faktor-faktor yang menentukan sifat alir adalah kerapatan jenis, bentuk partiket atau ukuran partikel dan kandungan lembab.

Berdasarkan hasil yang diperoleh dari pemeriksaan sifat fisik granul untuk uji waktu alir formula 1 dan formula 2 didapat bahwa kedua formula tersebut memenuhi syarat, karena waktu alir formula 1 selama 8,90 detik dan formula 2 selama 9,51 detik. Sehingga dapat dikatakan bahwa kedua formula tersebut memenuhi syarat uji waktu alir, yaitu untuk $100 \mathrm{~g}$ granul mengalirnya kurang dari 10 detik.

Setelah hasil uji waktu alir didapatkan, dilanjutkan dengan pengukuran sudut diam. Kedua hasil formula 1 dan formula 2 memenuhi syarat yaitu untuk formula 1 sudut diamnya $29,68^{\circ}$ dan formula 2 sudut diamnya $26,56^{\circ}$, dari hasil tersebut masuk kedalam range sangat mudah mengalir dan granul dikatakan 
Jurnal Ilmiah Ibnu Sina, 6(1), Maret 2021, 39-48

p-ISSN: 2502-647X; e-ISSN: 2503-1902

memenuhi syarat apabila granul kurang dari $45^{\circ}$.

buah pare yang dibuat dalam

Setelah dilakukan uji waktu alir, dilakukan lagi uji pengetapan yang mana Indeks pengetapan granul ditentukan setelah dilakukan penghentakan terhadap sejumlah granul sehingga diperoleh volume yang konstan.Pada saat volume konstan partikel serbuk berada pada kondisi paling mampat. Untuk uji pengetapan sendiri baik formula 1 maupun formula 2 yaitu memenuhi syarat yang mana $10 \%$ untuk formula 1 dan $11 \%$ untuk formula 2 dengan syarat uji pengetapan yaitu indeks pengetapan serbuk atau granul yang baik yaitu kurang dari $20 \%$ akan mempunyai sifat alir yang baik.

Granul yang telah dihasilkan dan telah dilakukan evaluasi granul kemudian dicetak dengan bobot 500 mg pertablet pada tekanan tertentu dengan mesin pencetak tablet.

Evaluasi tablet dilakukan pada penelitian ini bertujuan untuk mengetahui pengaruh penambahan amprotab sebagai penghancur dalam formulasi tablet akstrak buah pare dan untuk mengetahui mutu tablet ekstrak memenuhi persyaratan farmakope.

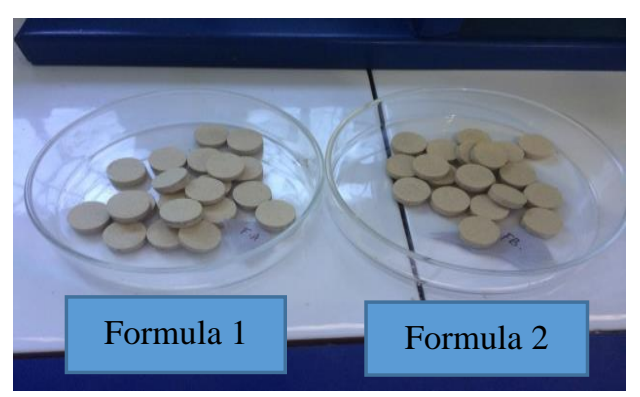

Gambar 1. Tablet Ekstrak Buah Pare Formula 1 dan Formula 2

Tabel 4. Hasil Uji Sifat Fisik Tablet

\begin{tabular}{clcc}
\hline \multirow{2}{*}{ No } & Uji Sifat & \multicolumn{2}{c}{ Formula } \\
\cline { 2 - 4 } & Fisik & \multicolumn{1}{c}{2} & 2 \\
\hline \multirow{2}{*}{1} & Kerapuhan & 0,64 & 1,73 \\
& $(\%)$ & $11,92 \pm$ & $6,33 \pm$ \\
\multirow{2}{*}{2} & Kekerasan & 2,68 & 0,73 \\
& $(\mathrm{~kg})$ & 8 menit & 7 menit \\
\multirow{2}{*}{3} & Waktu & 44 & 57 \\
& hancur & detik & detik \\
& Keseragaman & 514,60 & 543,47 \\
4 & bobot (mg) & $\pm 17,17$ & $\pm 18,52$ \\
\hline
\end{tabular}

Uji keseragaman bobot dilakukan untuk menentukan keseragaman isi ataupun kandungan bahan obat dalam setiap tablet serta membantu memastikan setiap tablet mengandung jumlah obat yang tepat (Sa'adah et al., 2019)

Variasi bobot tablet dipengaruhi oleh sifat alir granul semakin mudah mengalir suatu bahan maka akan semakin baik keseragaman bobotnya. Uji keseragaman bobot pada 
Jurnal Ilmiah Ibnu Sina, 6(1), Maret 2021, 39-48

p-ISSN: 2502-647X; e-ISSN: 2503-1902

penelitian ini masing-masing formula menggunakan 20 tablet. Berdasarkan evaluasi keseragaman bobot formula 1 dan formula 2 tidak ada satupun tablet yang menyimpang lebih besar dari 5\% dan tidak ada satupun tablet yang menyimpang lebih besar dari 10\%, sehingga dapat dinyatakan bahwa formula 1 dan formula 2 memenuhi syarat keseragaman bobot.

Berdasarkan hasil penelitian dapat dilihat nilai kekerasan tablet formula 1 menyimpang dari $4-8 \mathrm{~kg}$. sedangkan formula 2 yaitu memenuhi persyaratan uji kekerasan dengan hasil rata-rata yaitu $6,33 \mathrm{~kg}$. Menurut (Sulaiman, 2007) adapun hasil kekerasan, kerapuhan dan waktu hancur tablet sangatlah berkaitan, yang mana jika kekerasan tablet kurang dari $4 \mathrm{~kg}$ masih dapat diterima asalkan kerapuhannya tidak melebihi batas yang ditetapkan, begitupun sebaliknya dan kekerasan tablet yang lebih dari $10 \mathrm{~kg}$ masih dapat diterima, asalkan masih memenuhi persyaratan waktu hancur (desintegrasi) dan disolusi yang dipersyaratkan.

Kekerasan tablet juga dipengaruhi oleh beberapa faktor diantaranya: faktor kandungan pada serbuk (fines) pada saat pentabletan, dimana serbuk mempunyai daya kohesi antar partikel sehingga kekerasan akan lebih tinggi.

Hasil uji kerapuhan tablet diperoleh bahwa formula 1 memenuhi syarat uji kerapuhan dan formula 2 tidak memenuhi uji syarat kerapuhan yaitu kurang dari 1\%. Kerapuhan tablet dipengaruhi oleh banyaknya fines pada saat pembuatan granul. Semakin banyak fines, akan semakin tinggi angka kerapuhan karena fines tersebut berfungsi sebagai pengikat sekat yang mengurangi gaya adhesi antar partikel sehingga menyebabkan kerapuhan tablet meningkat (Andayana, 2009).

Hasil uji waktu hancur pada penelitian ini telah memenuhi syarat yang ada dalam Farmakope Indonesia edisi III yaitu tidak melebihi 15 menit. Hasil pengujian waktu hancur tablet ekstrak buah pare dengan bahan penghancur amprotab konsentrasi $8 \%$, dan $15 \%$ masing masing yaitu 9,1 menit dan 7,7 menit. Sesuai dengan teori, tablet akan semakin cepat larut dan hancur dengan bertambahnya jumlah bahan penghancur yang ditambahkan. Semakin lambat tablet 
Jurnal Ilmiah Ibnu Sina, 6(1), Maret 2021, 39-48

p-ISSN: 2502-647X; e-ISSN: 2503-1902

dalam mengabsorbsi air, semakin

lama bahan penghancur bekerja sehingga semakin lama pula waktu hancurnya.

\section{KESIMPULAN}

Adapun kesimpulan dalam penelitian ini yaitu:

1. Amprotab pada konsentrasi $8 \%$ dan $15 \%$ mampu bertindak sebagai bahan penghancur dalam formulasi tablet ekstrak buah pare.

2. Tablet ekstrak buah pare yang dihasilkan yang memenuhi persyaratan mutu fisik tablet adalah formula 1.

\section{UCAPAN TERIMA KASIH}

Terima kasih kepada Fakultas Farmasi Universitas Muhammadiyah Banjarmasin yang telah memfasilitasi dalam pelaksanaan penelitian ini.

\section{DAFTAR PUSTAKA}

Andayana, N. (2009). Teori Sediaan Tablet. Jakarta: Penerbit Dunia Farmasi.

Anonim. (1979).
Indonesia, Edisi $\quad$ III,
Departemen Kesehatan Republik Indonesia, Jakarta.

Anonim. (1995). Farmakope Indonesia, Edisi IV, Departemen Kesehatan Republik Indonesia, Jakarta.

Grover, J.K., Yadav, S., Vats, V. (2002). Medical Plants of India with Anti-diabetic Potential. Journal of Ethnopharmacology, 81(1), 81-100.

Jaya, A. (2007). Ekstrak Buah Pare untuk Penderita Diabetes Militus. Media Informasi Kesehatan, 4, 220-222.

Rowe, R, C., Sheskey, P.J., dan Weller, P. J. (2009). Handbook of Pharmaceutical Excipients. Edisi VI. London: PublisherScience and Practice Royal Pharmaceutical Society of Great Britain.

Sa'adah, H., S, Y. B., \& Sandra, A. A. (2019). Formulasi Orally Desintegrating Tablet (ODT) Asetosal dengan Variasi Konsentrasi Kombinasi Avicel PH 102 dan Manitol sebagai Bahan Pengisi. 4(1), 31-39.

Siregar, C.J.P., \& Wikarsa, S. (2010). Teknologi Farmasi Sediaan Tablet. Jakarta: Penerbit Buku Kedokteran EGC.

Sulaiman, T. N. S. (2007). Teknologi dan Formulasi Sediaan Padat. Pustaka Laboratorium Teknologi Farmasi Fakultas Farmasi UGM. Yogyakarta. 